RESEARCH ARTICLE

\title{
Studies on organic non-covalent binders of $\beta$-sitosterol
}

\section{P. R. Wijemanne ${ }^{1}$, P. M. Jayaweera ${ }^{2}$ and E. R. Jansz ${ }^{3 *}$}

1 Department of Biochemistry, Faculty of Medical Sciences, University of Sri Jayewardenepura, Gangodawila, Nugegoda.

2 Department of Chemistry, Faculty of Applied Sciences, University of Sri Jayewardenepura, Gangodawila, Nugegoda.

3 29/1, Pietersz Place, Nugegoda.

\begin{abstract}
The $\beta$-sitosterol moiety was known to bind acyclic carotenoids phytoene and phytofluene. Recently it was reported that impurities of $\beta$-sitosterol from plant sources ruled out isolation from those sources. These studies showed that common $\beta$-sitosterol contained many impurities which can be separated by using a chromatotron. Studies also showed that $\beta$-sitosterol on binding to phytofluene quenched the latter's fluorescence by forming a complex with $\log \mathrm{K}_{\text {ass }}=5.0$. This complex does not significantly alter the fine structure of the phytofluene IR spectrum indicating no significant distortion in the condensed phase.
\end{abstract}

Keywords: $\beta$-sitosterol, binders, phytofluene, quenching, fluorescence.

\section{INTRODUCTION}

$\beta$-sitosterol is one of the most abundant phytosterols in plants, which along with campesterol accounts for about $95 \%$ of total steroids in plants ${ }^{1}$. In addition, $\beta$-sitosterol serves as the common aglycone of flabelliferins, a group of steroidal saponins found in palmyrah fruit pulp (PFP $)^{2}$. An interesting feature of all flabelliferins is that they are always naturally associated with a fluorescent binder ${ }^{3}$. In palmyrah fruit pulp this is an acyclic fluorescent carotene phytoene or phytofluene ${ }^{4}$. The importance of this fluorescent impurity is that it can affect the bioactivity of flabelliferins in $\mathrm{PFP}^{3}$, while the fluorescent complex of palmyrah flour shows neurotoxic activity in rats ${ }^{5}$.

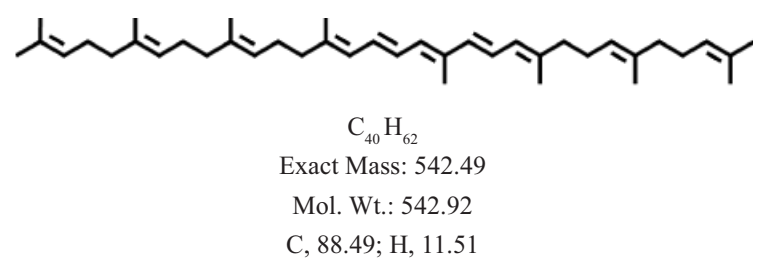

Figure 1: Phytofluene
A recent report stated that $\beta$-sitosterol was difficult to purify due to the presence of other steroids ${ }^{6}$. Our hypothesis was that the impurities were not only other steroids but also compounds that bind to the steroid nucleus. Computer modelling studies have shown that phytoene and phytofluene could bind with $\beta$-sitosterol ${ }^{7}$. The objectives of this study were to determine; (i) whether $\beta$-sitosterol from a reputed manufacturer in USA had binding compounds, (ii) whether the binders were phytofluene or phytoene, (iii) whether phytofluene could bind to $\beta$-sitosterol in vitro and if so (iv) the association constant of the binding.

\section{METHODS AND MATERIALS}

$\beta$-sitosterol was obtained from Sigma, St. Louis, USA.

Isolation of Phytofluene: Palmyrah fruit was collected randomly on site from Kalpitiya, extracted manually, and mixed well to give pulp(PFP). PFP( $50 \mathrm{~g})$ was ground with an adequate amount of celite and acetone $(100 \mathrm{~mL} \times 3)$ and filtered under suction until the PFP exhibited no discernable colour. The final acetone extract of carotenoids $(300 \mathrm{~mL})$ was extracted into hexane in a separatory funnel and residual acetone was washed using distilled water. The hexane extract was concentrated under vacuum using a rotary evaporator and flushed with nitrogen gas to remove oxygen. Open Column Chromatography (OCC) was performed with a column of $\mathrm{MgO}$ : celite (1:1) matrix (activated by heating at $110{ }^{\circ} \mathrm{C}$ for $4 \mathrm{~h}$ ) tightly packed under reduced pressure into a height of $12 \mathrm{~cm}$ in a glass column. Anhydrous $\mathrm{Na}_{2} \mathrm{SO}_{4}$ was added on top to a height of $1 \mathrm{~cm}$. After equilibrating the column with hexane and under applied pressure the carotenoid extract was added on to the $\mathrm{Na}_{2} \mathrm{SO}_{4}$ layer with a pipette and left to absorb into it. The extract was eluted with hexane and fractions were collected into dark bottles ${ }^{8}$.

\footnotetext{
${ }^{*}$ Corresponding author
} 
Phytofluene is a colourless carotenoid and only the colourless fractions which eluted first (fractions 1 and 2) were collected and analyzed by the UV-Visible double beam spectrophotometer (Shimadzu, UV-1601). The spectrum of each fraction was analyzed for the characteristic shape of phytofluene given in the literature and the three $\lambda_{\max }$ wavelengths of phytofluene at $331 \mathrm{~nm}$, $348 \mathrm{~nm}$ and $367 \mathrm{~nm}$. The fractions that satisfied the above criteria were pooled together and the amount of phytofluene was calculated using the equation given below ${ }^{8}$.

$$
\begin{aligned}
\mathrm{X}(\mu \mathrm{g})= & \mathrm{A} \cdot \mathrm{y}(\mathrm{mL}) \times 10^{6} \\
& \mathrm{~A}^{1 \%}{ }_{1 \mathrm{~cm}} \times 100
\end{aligned}
$$

Where; X - Amount of the carotenoid

A - Absorbance of the fraction

y - Volume of the fraction

$\mathrm{A}^{1 \%}{ }_{1 \mathrm{~cm}}-$ Absorption coefficient of the carotenoid in the solvent used

Reaction of Phytofluene with $\beta$-sitosterol: A $\beta$-sitosterol solution with a concentration of $1 \mathrm{mg}$ in $5 \mathrm{~mL}$ of methanol $(\mathrm{MeOH})$ was prepared. The phytofluene solution of concentration $100 \mu \mathrm{g}$ in $1 \mathrm{~mL} \mathrm{MeOH}$ was prepared by dissolving the isolated phytofluene $(284 \mu \mathrm{g})$ from PFP in $2.84 \mathrm{~mL}$ of $\mathrm{MeOH}$ (Phytofluene and $\beta$-sitosterol were mixed and placed in a dark environment overnight).

The mixture was concentrated by gently flushing with nitrogen and reducing the volume to less than $0.5 \mathrm{~mL}$ in an Eppendorf tube. Using this solution Thin Layer Chromatography (TLC) was performed. Volumes of 5, 10, 20,30 and $50 \mu \mathrm{L}$ were spotted on to TLC paper (Whatman No.1). The plate was developed using the solvent system of butanol: ethanol: ammonia (7:3:4) ${ }^{9}$. After drying the TLC paper, presence of fluorescence was ascertained by illuminating with $280 \mathrm{~nm}$ UV light. The presence of $\beta$-sitosterol was determined by spraying with a freshly prepared anisaldehyde $/ \mathrm{H}_{2} \mathrm{SO}_{4}$ solution and heating at $105^{\circ} \mathrm{C}$ for $10 \mathrm{~min}$ for the development of dark spots.

Chromatotron (Harrison Research, California, Model 7924T): A rotor plate of $2 \mathrm{~mm}$ thickness was prepared by mixing of $\mathrm{G}_{60} \mathrm{PF}_{254}$ silica $(50 \mathrm{~g})$ in distilled water $(110 \mathrm{~mL})$. The plate was activated at $110{ }^{\circ} \mathrm{C}$ for $30 \mathrm{~min}$ just before it was used for the chromatotron run. For the eluent a methanol: propan-1-ol (1:1) mixture was used ${ }^{9}$. $\beta$-sitosterol $(0.5 \mathrm{mg})$ dissolved in $1 \mathrm{~mL}$ of methanol was eluted at a flow rate of $6 \mathrm{~mL} / \mathrm{min}$ (FMI Lab Pump, Fluid Metering Inc, Model QD serial \# 44 L 37672R), and 30 fractions of $2 \mathrm{~mL}$ each were collected.
Analysis of fractions: Fluorescence was detected by illuminating the fractions with $280 \mathrm{~nm}$ UV light. The presence of $\beta$-sitosterol was detected by spotting fractions on chromatography paper (Whatman No.1), spraying with a freshly prepared anisaldehyde reagent and heating at $105^{\circ} \mathrm{C}$ for $10 \mathrm{~min}$, to ascertain the presence of $\beta$-sitosterol. Rotor plate of the chromatotron was also treated in the same manner to detect any residual $\beta$-sitosterol.

Reverse Phase High Performance Liquid Chromatograph (RP-HPLC): Fluorescent fractions were pooled, concentrated and $20 \mu \mathrm{L}$ of each was injected into the HPLC (Waters). An isocratic solvent system of acetonitrile: methanol : tetrahydrofuran $(58: 35: 7)$ was used as mobile phase while a C18 column $(250 \mathrm{~mm} \times 4.6 \mathrm{~mm})$ was used as stationary phase. A flow rate of $1 \mathrm{~mL} / \mathrm{min}$ (Waters HPLC pump, Model code 515, serial no. D 515423 M) was maintained and detected at $286 \mathrm{~nm}$ and $330 \mathrm{~nm}$ (Waters 2487 Dual $\lambda$ Absorbance detector). A mixture of phytoene and phytofluene was used as the standard.

Measurement of quenching by spectroflourimetry: Association constant for the reaction between phytofluene and $\beta$-sitosterol was determined by analyzing the quenching effect of $\beta$-sitosterol on the fluorescence of phytofluene. The solutions used for the test were, a solution of phytofluene $(0.040 \mathrm{mg} / \mathrm{mL})$ and a solution of $\beta$-sitosterol $(0.025 \mathrm{mg} / \mathrm{mL})$. The $\beta$-sitosterol used was those purified by separating the fluorescent impurity using the chromatotron. Fluorescence was determined by an Aminco-Bowman Series 2 Luminescence Spectrometer and analysed by AB2 software. The fluorescence of phytofluene $(2.0 \mathrm{~mL})$ was measured, exciting at $366 \mathrm{~nm}$ and scanning the emission spectrum. $\beta$-sitosterol was added to the phytofluene in the cell using a micropipette and emission spectrum was obtained each time. For the whole series of fluorescence measurement the exact parameters (i.e. excitation wavelength, excitation voltage and bandpass) observed for phytofluene alone was kept constant throughout.

Calculation of the association constant using the Stern-Volmer Plot ${ }^{10}$ : The Stern-Volmer plot was used for calculating the association constant for the complex by plotting the concentration of $\beta$-sitosterol against the quantum yield ratio $\left(\Phi_{\mathrm{f}}^{0} / \Phi_{\mathrm{f}}\right)$. Quantum yield ratio can be calculated using the equation,

$$
\Phi_{\mathrm{f}}^{0} / \Phi_{\mathrm{f}}=\mathrm{A}_{0} / \mathrm{A}
$$

Where; $\Phi_{\mathrm{f}}^{0}$ - quantum yield of phytofluene in the absence of $\beta$-sitosterol

$\Phi_{\mathrm{f}}-$ quantum yield of phytofluene in the presence of $\beta$-sitosterol

$A_{0}-$ peak area when no $\beta$-sitosterol is present in the phytofluene

Journal of the National Science Foundation of Sri Lanka 35 (4) 


$$
\begin{aligned}
& \text { A - peak area at different } \beta \text {-sitosterol } \\
& \text { concentrations. }
\end{aligned}
$$

The association constant was calculated with the equation,

$$
\Phi_{\mathrm{f}}^{0} / \Phi_{\mathrm{f}}=\mathrm{K}_{\text {ass }}[\mathrm{Q}]+1
$$

Where; $\mathrm{K}_{\text {ass }}$ - association constant

[Q] - concentration of the quencher ( $\beta$-sitosterol)

Infrared spectroscopic analysis of $\beta$-sitosterolphytofluene complex: Solutions of concentration 0.025 $\mathrm{mg} / \mathrm{mL}$ in methanol were prepared using phytofluene and purified $\beta$-sitosterol. Equivalent volumes of the two solutions were mixed and kept overnight. Phytofluene solution ( $1 \mathrm{~mL}), \beta$-sitosterol solution $(1 \mathrm{~mL})$ and a solution containing the mixture of phytofluene and $\beta$-sitosterol $(1 \mathrm{~mL})$ were separately evaporated to dryness by flushing with nitrogen. The residue of each solution was mixed with $\mathrm{KBr}$ (Merck, art. 4097) in 1: 100 proportions and

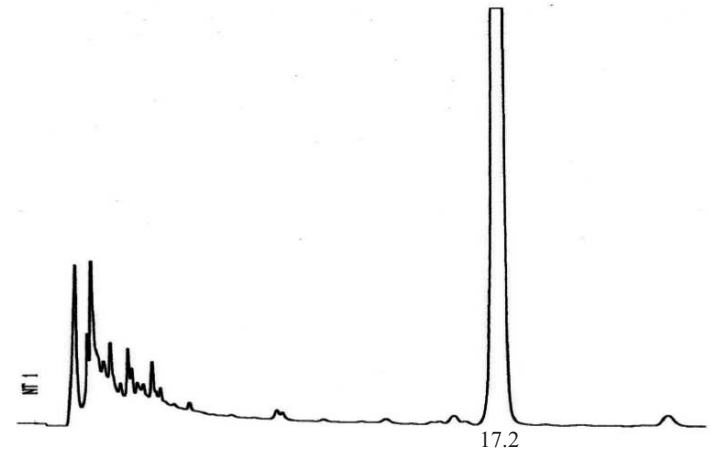

Figure 1: Peaks given by impurities at $286 \mathrm{~nm}$ pressed into a clear, thin $\mathrm{KBr}$ pellet in a steel pellet maker. Each pellet was scanned by a Fourier Transformed Infrared (FT-IR) spectrometer. A Thermo Nicolet Avatar 320 FT-IR was used for scanning and EZ-OMNIC software was used for data processing and analysis. $\mathrm{KBr}$ background scanning was performed beforehand to subtract any absorption peaks due to $\mathrm{KBr}$ alone.

\section{RESULTS}

\section{Fluorescent compound of $\beta$-sitosterol standard}

$\beta$-sitosterol showed fluorescence on spotting on chromatographic paper. The binders were separated by the chromatotron and the binder was analyzed by RP-HPLC (Figure1).

The fluorescent compound gave peaks at 2.1, 2.7, 4.9 retention time (RT) at $330 \mathrm{~nm}$ and peaks at $2.1(4.4 \%), 2.5$ (1.3\%), 2.7 (4\%), $3.2(1.5 \%), 3.4(2.0 \%), 3.8(0.5 \%)$, $4.1(1.1 \%), 4.2(0.6 \%), 4.4(1.1 \%), 4.9(0.9 \%), 5.2$ (0.3\%), 6.2 (0.1\%), 17.2 (79.7\%), 23.4 (0.8\%) RT. Phytoene and phytofluene standards showed peaks at 42.1 and 42.5 respectively at $330 \mathrm{~nm}$.

\section{Reaction of $\beta$-sitosterol with phytofluene}

$\beta$-sitosterol $(80 \mu \mathrm{g})$ was reacted with phytofluene $(37 \mu \mathrm{g})$ in $870 \mu \mathrm{L}$. The spot containing fluorescence and anisaldehyde positive spot were same on the TLC showing that the complex was formed. It was noted that the spots of phytofluene was much larger than $\beta$-sitosterol due to higher sensitivity of fluorescence.

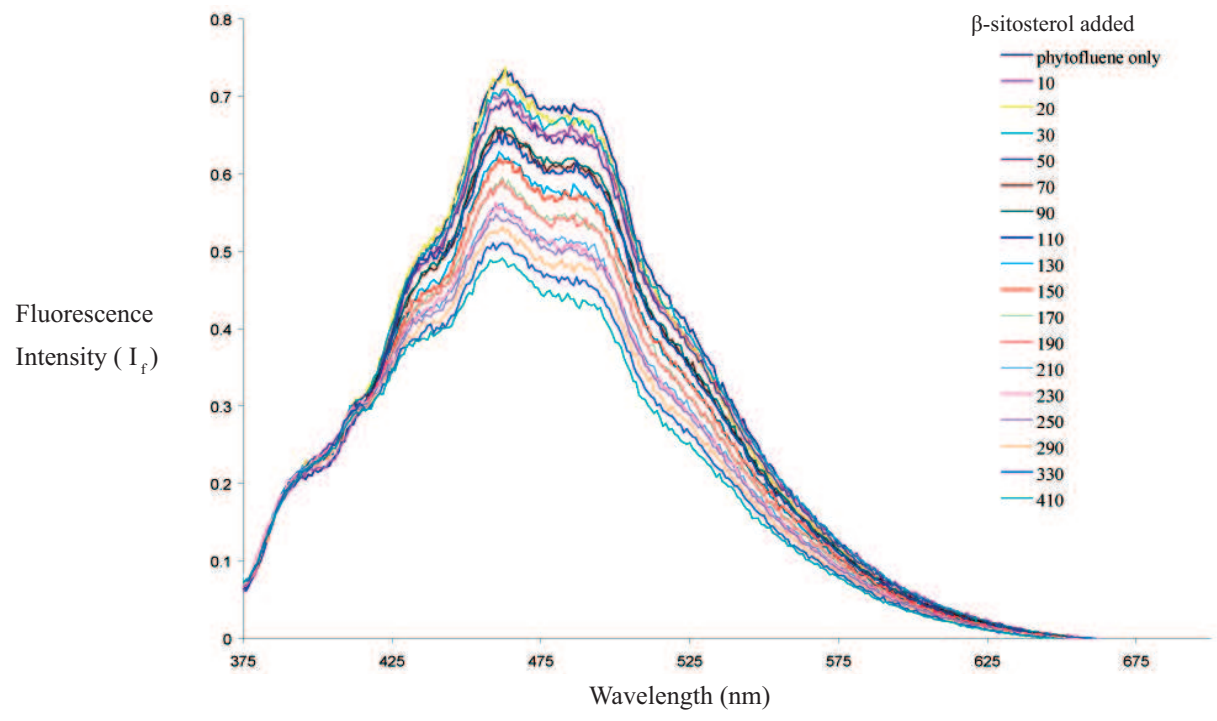

Figure 2: Fluorescence quenching of phytofluene by $\beta$-sitosterol 


\section{Quenching studies}

Addition of $\beta$-sitosterol to phytofluene showed gradual reduction of fluorescence emitted by phytofluene (Figure 2). For the Stern-Volmer plot, peak area of fluorescence was chosen. From the plotted graph an equation of $y=108674 x+1.0059$ was given with a linear regression of $\mathrm{R}^{2}=0.9817$. From the slope of the graph $\mathrm{K}_{\text {ass }}=\log 1.1 \times 10^{5}$, hence $\log \mathrm{K}_{\text {ass }}=5.0$.

\section{FT-IR studies}

The infrared spectroscopic differences between the complex and phytofluene are minimal compared to those between complex and $\beta$-sitosterol. The characteristics of $\beta$-sitosterol are notable at peaks of $1460 \mathrm{~cm}^{-1}, 1380$ $\mathrm{cm}^{-1}, 1050 \mathrm{~cm}^{-1}$ and $960 \mathrm{~cm}^{-1}$. Phytofluene showed peaks at $1750 \mathrm{~cm}^{-1}, 1460 \mathrm{~cm}^{-1}, 1380 \mathrm{~cm}^{-1}$ and $1160 \mathrm{~cm}^{-1}$. while the complex showed significant peaks at $1750 \mathrm{~cm}^{-1}$, $1460 \mathrm{~cm}^{-1}, 1380 \mathrm{~cm}^{-1}$ and $1160 \mathrm{~cm}^{-1}$.

\section{DISCUSSION}

The peaks at $330 \mathrm{~nm}$ by the fluorescent compound (2.1, 2.7, and 4.9) showed no correlation with the retention times of either phytoene (42.1) or phytofluene (42.5). Hence phytoene and phytofluene are not the compounds responsible for fluorescence. Furthermore, at $286 \mathrm{~nm}$ the fluorescent compound yielded a wide range of peaks, which leads to conclude that the impurity may not be just one compound but an array of compounds. However as it is possible to separate impurities from $\beta$-sitosterol by using a chromatotron as described, there is no need to go to lengths of developing a synthetic method for $\beta$-sitosterol production ${ }^{6}$.

Quenching studies confirmed the binding of phytofluene to $\beta$-sitosterol took place with a logarithmic association constant of 5.0. The FT-IR spectra of $\beta$-sitosterol and the complex showed slight variations at $1050 \mathrm{~cm}^{-1}$ and $960 \mathrm{~cm}^{-1}$ indicating that there was some distortion of $\beta$-sitosterol on binding but the distortion is not significant.

It is interesting to note that flabelliferin-II (F-II), a tetraglycoside of $\beta$-sitosterol did not bind with phytofluene in vitro ${ }^{11}$ and the binding of F-II to phytofluene was not favourable by computer modelling studies ${ }^{11}$. Yet the F-II- phytofluene complex is found naturally in palmyrah fruit pulp ${ }^{2}$. It had been speculated ${ }^{11}$ that $\beta$-sitosterol binds phytofluene first and thereafter the rest of the carbohydrate moiety is synthesized. The binding of $\beta$-sitosterol moiety has significance as these affect antimicrobial and AT Pase inhibition activity of flabelliferins ${ }^{3}$ and has also been suggested to be the basis of the pro-toxin producing the neurotoxic effect of palmyrah flour ${ }^{4,5}$.

\section{Acknowledgement}

The authors thank IPICS SRI: 07 for funds.

\section{References}

1. Piironen V., Toivo J., Puupponen-Pimia R. \& Lampi A. (2003). Plant sterols in vegetables, fruits and berries. Journal of the Science of Food and Agriculture. 83: 330 337.

2. Ariyasena D.D. (2002). The diversity, bioactivity and structural studies of flabelliferins form palmyrah (Borassus flabellifer) fruit pulp, M. Phil. Thesis, University of Sri Jayewardenepura, Gangodawila.

3. Uluwaduge D.I., Keerthi A.A.P., Senadheera S.N. \& Jansz E.R. (2005). Studies on the natural hydrophobic binder of flabelliferins and their effect on some bioactivities. Journal of the National Science Foundation, Sri Lanka 33 (3): 187 191.

4. Bandara T. (2004). Studies on the fluorescent complex of palmyrah flour. Final year Human Biology project report. University of Sri Jayewardenepura, Gangodawila.

5. Wickramasekara N.T. \& Jansz E.R. (2003). The range of steroidal saponins of palmyrah flour: could they contribute to toxic effects on consumers. Journal of Science, Eastern University of Sri Lanka 3: 11 - 18.

6. McCarthy F.O., Chopra J., Ford A., Hogan S.A., Kerry J.P., O'Brien N.M., Ryan E. \& Maguire A.R. (2005). Synthesis, isolation and characterisation of $\beta$-sitosterol and $\beta$-sitosterol oxide derivatives. Organic \& Biomolecular Chemistry 3: 3059 - 3065.

7. Jayaweera P.M., Chandrika U.G. \& Jansz E.R. (2004). Computational evidence for the reversible non electrostatic hydrophobic binding of $\beta$-sitosterol with acyclic carotenes. Chemistry in Sri Lanka. 22: 15 - 17.

8. Rodriguez-Amaya D.B. (1999). A Guide to Carotenoid Analysis in Foods. ISLI press, Washington.

9. Ariyasena D.D., Nikawela J.K., Jansz, E.R. \& Abeysekara A.M. (2002). Separation techniques of flabelliferins from palmyrah (Borassus flabellifer L) fruit pulp. Journal of Science, Eastern University of Sri Lanka. 1: 1 - 9.

10. Atkins P.W. (1998). Physical Chemistry. 6th edition. Oxford University Press, Oxford, 26: 799 - 802.

11. Uluwaduge D.I. (2005). An investigation of palmyrah (Borassus flabellifer L) fruit pulp mediated inhibition of intestine glucose uptake and its toxicity. Ph.D. Thesis, University of Sri Jayewardenepura, Gangodawila. 